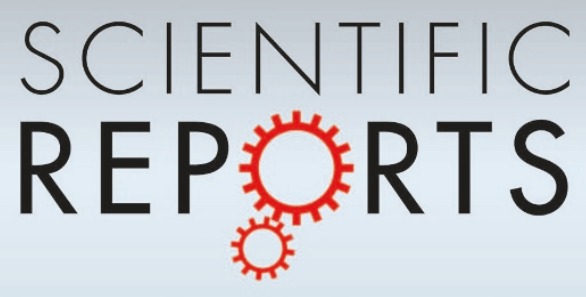

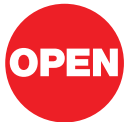

SUBJECT AREAS:

PHOTOCHEMISTRY

CARBON NANOTUBES AND

FULLERENES

SURFACE CHEMISTRY

SPECTROSCOPY

Received

29 June 2012

Accepted

14 September 2012

Published

4 October 2012

Correspondence and requests for materials should be addressed to X.G. lguoxf@pku.edu. $\mathrm{cn}$ )

\title{
Direct Optical Characterization of Graphene Growth and Domains on Growth Substrates
}

\author{
Chuancheng Jia' ${ }^{1}$ Jiaolong Jiang' ${ }^{1}$ Lin Gan' \& Xuefeng Guo ${ }^{1,2}$
}

\begin{abstract}
${ }^{1}$ Center for Nanochemistry, Beijing National Laboratory for Molecular Sciences (BNLMS), State Key Laboratory for Structural Chemistry of Unstable and Stable Species, College of Chemistry and Molecular Engineering, Peking University, Beijing 100871, P. R. China, ${ }^{2}$ Department of Advanced Materials and Nanotechnology, College of Engineering, Peking University, Beijing 100871, P. R. China.
\end{abstract}

We detailed a facile detection technique to optically characterize graphene growth and domains directly on growth substrates through a simple thermal annealing process. It was found that thermal annealing transformed the naked $\mathrm{Cu}$ to $\mathrm{Cu}$ oxides while keeping graphene and graphene-covered $\mathrm{Cu}$ intact. This increases the interference color contrast between $\mathrm{Cu}$ oxides and $\mathrm{Cu}$, thus making graphene easily visible under an optical microscope. By using this simple method, we studied the factors that affect graphene nucleation and growth and achieved graphene domains with the domain size as large as $\sim 100 \mu \mathrm{m}$. The concept of chemically making graphene visible is universal, as demonstrated by the fact that a solution process based on selective $\mathrm{H}_{2} \mathrm{O}_{2}$ oxidation has been developed to achieve the similar results in a shorter time. These techniques should be valuable for studies towards elucidating the parameters that control the grains, boundaries, structures and properties of graphene.

\footnotetext{
- or large-area high-quality graphene growth, developing an effective detection technique for understanding - the growth mechanisms is a prerequisite. In this study, we found a convenient optical method to directly characterize graphene domains and domain boundaries on growth substrates through selective oxidation for improving the growth conditions (Figure 1a). The unique features of graphene utilized here are its remarkable impermeability, thermal/chemical stability, and optical transparency in the visible region. Together with its other unusual electrical and mechanical properties, these properties have motivated intensive researches of graphene in physics, chemistry, and materials science in a short period ${ }^{1-5}$. In fact, graphene has been widely used as a key material in high-speed electronics ${ }^{6,7}$, flexible electronics ${ }^{5}$ and optoelectronics ${ }^{8,9}$ and holds the promise in future as a replacement material for silicon when silicon-based electronic technology reaches its quantum limits ${ }^{10}$. To this end, many synthetic methods have been developed and extensively explored in the past few years for meeting the great demand for large-area high-quality graphene, including the Scotch Tape peeling-off technique ${ }^{11}$, the hightemperature sublimation of $\mathrm{SiC}^{12}$, the intercalation of graphite ${ }^{13}$, the reduction from graphene oxides and derivatives $^{3}$, the segregation from metal alloys ${ }^{14}$, and the metal-catalyzed chemical vapor deposition ${ }^{15}$. Of particular interest is the work by $\mathrm{Li}$ and colleagues ${ }^{4}$, where large-scale graphene with high quality were grown on copper foils through a surface adsorption-dominated chemical vapor deposition (CVD) process. Recently, by using the same method, micrometer-size individual single-crystal graphene domains with various shapes, such as hexagonal ${ }^{16-18}$ and rectangular ${ }^{19,20}$, or large-area polycrystalline films ${ }^{4}$ have been achieved. However, the characterization of these interesting domains need complex techniques, for example, SEM ${ }^{4,17}, \mathrm{TEM}^{21}, \mathrm{STM}^{22}, \mathrm{LEEM}^{23}, \mathrm{AFM}^{11}, \mathrm{Raman}^{24}$, and $\mathrm{EBSD}^{25,26}$. In some cases, only after transferred onto the $\mathrm{SiO}_{2} / \mathrm{Si}$ substrate with suitable thickness of a $\mathrm{SiO}_{2}$ layer ${ }^{27}$ or treated with nematic liquid crystals ${ }^{28}$, graphene domains could be observed by an optical method. It is the lack of a convenient detection technique for growth monitoring that hampers deeper understanding of the factors that control graphene growth, such as graphene nucleation, temperature, gas feeding rate, and pressure. The major advantage of the optical detection technique developed in the current study is its simplicity that allows holistic considerations of all the factors for optimizing growth conditions and thus controlling graphene quality.
}

\section{Results}

Graphene visualization through selective oxidation. Graphene is transparent enough to allow the path of the

visible light, which changes the interference color in contrast to the empty substrate. This can explain why 

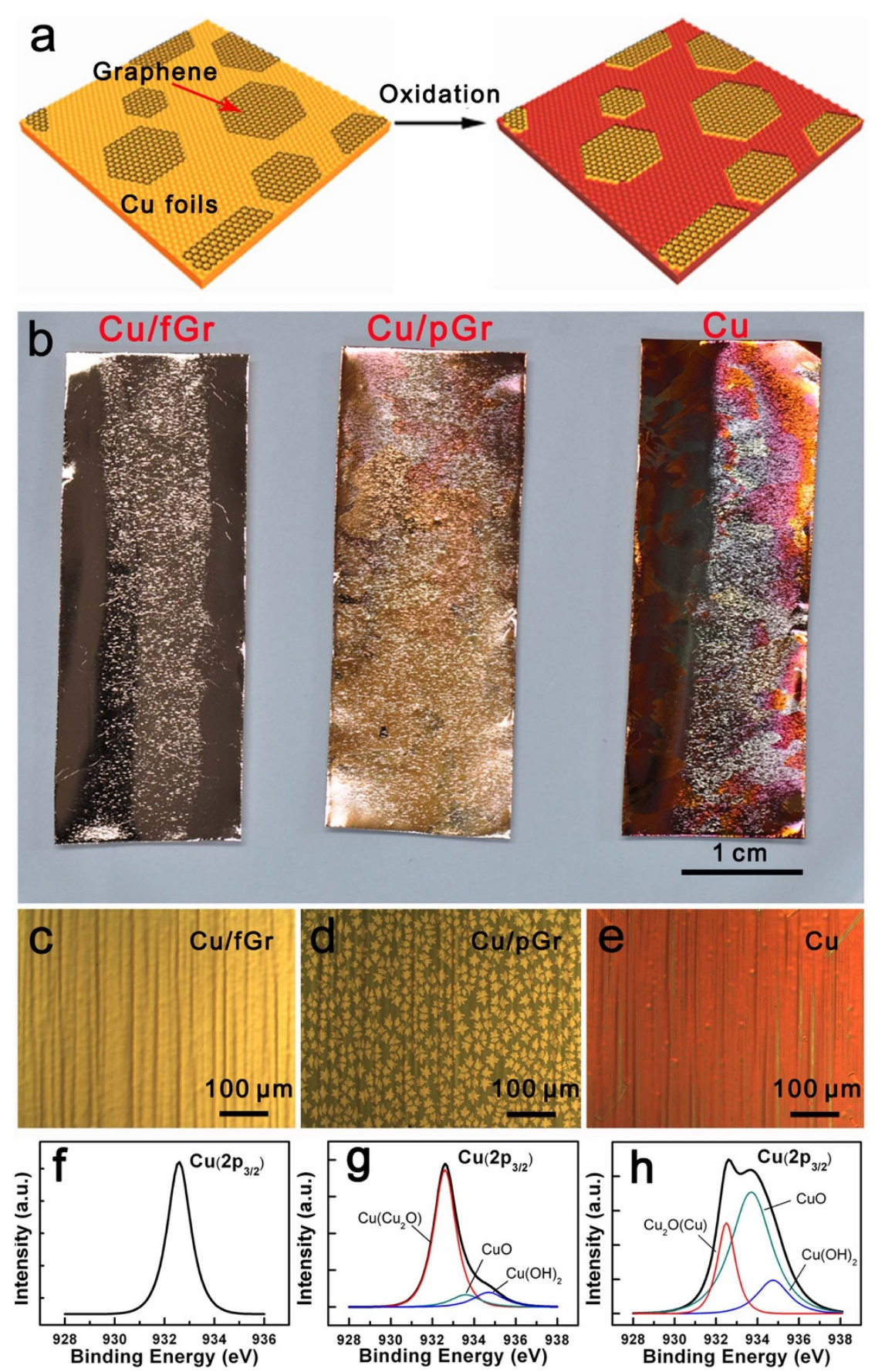

Figure 1 Optical visualization of graphene directly on growth substrates. (a) A schematic illustration of how to optically characterize graphene domains directly on $\mathrm{Cu}$ foils through selective oxidation. (b) Photographs of $\mathrm{Cu}$ foils covered with fully grown graphene (Cu/fGr), with partially grown graphene $(\mathrm{Cu} / \mathrm{pGr})$ and without graphene after annealing in air $\left(160^{\circ} \mathrm{C}, 6 \mathrm{~min}\right)$. (c-e) Optical microscopic images of Cu/fGr $(\mathrm{c}), \mathrm{Cu} / \mathrm{pG}(\mathrm{d})$, and $\mathrm{Cu}(\mathrm{e})$ foils after annealing. (f-h) XPS core-level $\mathrm{Cu} 2 \mathrm{p}_{3 / 2}$ spectra of $\mathrm{Cu} / \mathrm{fGr}(\mathrm{f}), \mathrm{Cu} / \mathrm{pG}(\mathrm{g})$, and $\mathrm{Cu}(\mathrm{h})$ foils after annealing.

graphene, even for a single-layer graphene, can be visualized under an optical microscope by the naked eyes on silicon wafers with a certain thickness of $\mathrm{SiO}_{2}$ but only after multistep chemical treatments and complex transfer processes from growth substrates such as $\mathrm{Cu}$ foils. The method we developed in this study is to optically detect graphene domains and domain boundaries directly on Cu foils through a simple selective annealing oxidation without further chemical treatments and transfer operations. The overall process for the selective annealing oxidation on $\mathrm{Cu}$ foils is shown in Fig. 1a. Because graphene has good thermal stability and impermeability ${ }^{29}$, under the proper annealing temperature (below $400^{\circ} \mathrm{C}$ ) in air, graphene not only keep itself pristine without oxidation, but protects the surface of
$\mathrm{Cu}$ foils that is covered by graphene from oxidation. In contrast, due to the high chemical activity of $\mathrm{Cu}$, the bare surface of $\mathrm{Cu}$ foils is oxidized to form $\mathrm{Cu}$ oxides, thus leading to significant changes in color. Therefore, the changes in color of $\mathrm{Cu}$ foils make graphene easily visible by the naked eyes using any common optical microscope as experimentally demonstrated below. For better comparison, the pure $\mathrm{Cu}$ foils without graphene $(\mathrm{Cu})$, with partial graphene growth $(\mathrm{Cu} / \mathrm{pGr})$ and with full graphene growth $(\mathrm{Cu} / \mathrm{fGr})$ by a low pressure chemical vapor deposition (LPCVD) method at $1020^{\circ} \mathrm{C}$ were used. Before annealing, from both the photography images and optical microscopic images, all the samples looked similar (Supplementary Fig. S1). However, after annealing in air at $160^{\circ} \mathrm{C}$ 
for $6 \mathrm{~min}$, the $\mathrm{Cu} / \mathrm{fGr}$ sample showed little color changes while the $\mathrm{Cu} / \mathrm{pGr}$ sample changed to be brown madder and the pure $\mathrm{Cu}$ sample changed dramatically to be gray red in a large area (Fig. 1b). Consistently, in a small scale under an optical microscope, the $\mathrm{Cu} /$ fGr sample also looked the same as before annealing (Fig. 1c), but the pure $\mathrm{Cu}$ sample changes to be uniformly red (Fig. 1e). Remarkably, on the $\mathrm{Cu} / \mathrm{pGr}$ sample, yellow graphene flakes with different shapes that were dispersed on the foliage green substrate was easily observed by the naked eyes directly on Cu foils (Fig. 1d).

Analysis of the oxidation mechanism. X-ray photoelectron spectroscopy (XPS) was used to analyze the surface compositions of the samples after annealing. The XPS spectrum of the $\mathrm{Cu} / \mathrm{fGr}$ sample shows a single peak with binding energy at $932.6 \mathrm{eV}$ (Fig. 2f), which corresponds to the $\mathrm{Cu} 2 \mathrm{p}_{3 / 2}$ peak of $\mathrm{Cu}$. For the $\mathrm{Cu} / \mathrm{pGr}$ and $\mathrm{Cu}$ samples (Figs. $2 \mathrm{~g}$ and $2 \mathrm{~h}$ ), the $\mathrm{Cu} 2 \mathrm{p}_{3 / 2}$ spectra were fitted with several peaks after annealing, which correspond to the formation of different $\mathrm{Cu}$ oxides, $\mathrm{Cu}_{2} \mathrm{O}(932.5 \mathrm{eV}), \mathrm{CuO}(933.7 \mathrm{eV})$, and $\mathrm{Cu}(\mathrm{OH})_{2}(934.7 \mathrm{eV})^{30,31}$. As the peaks for $\mathrm{Cu}(932.6 \mathrm{eV})$ and $\mathrm{Cu}_{2} \mathrm{O}$ $(932.5 \mathrm{eV})$ are very close to each other, they are displayed as a single
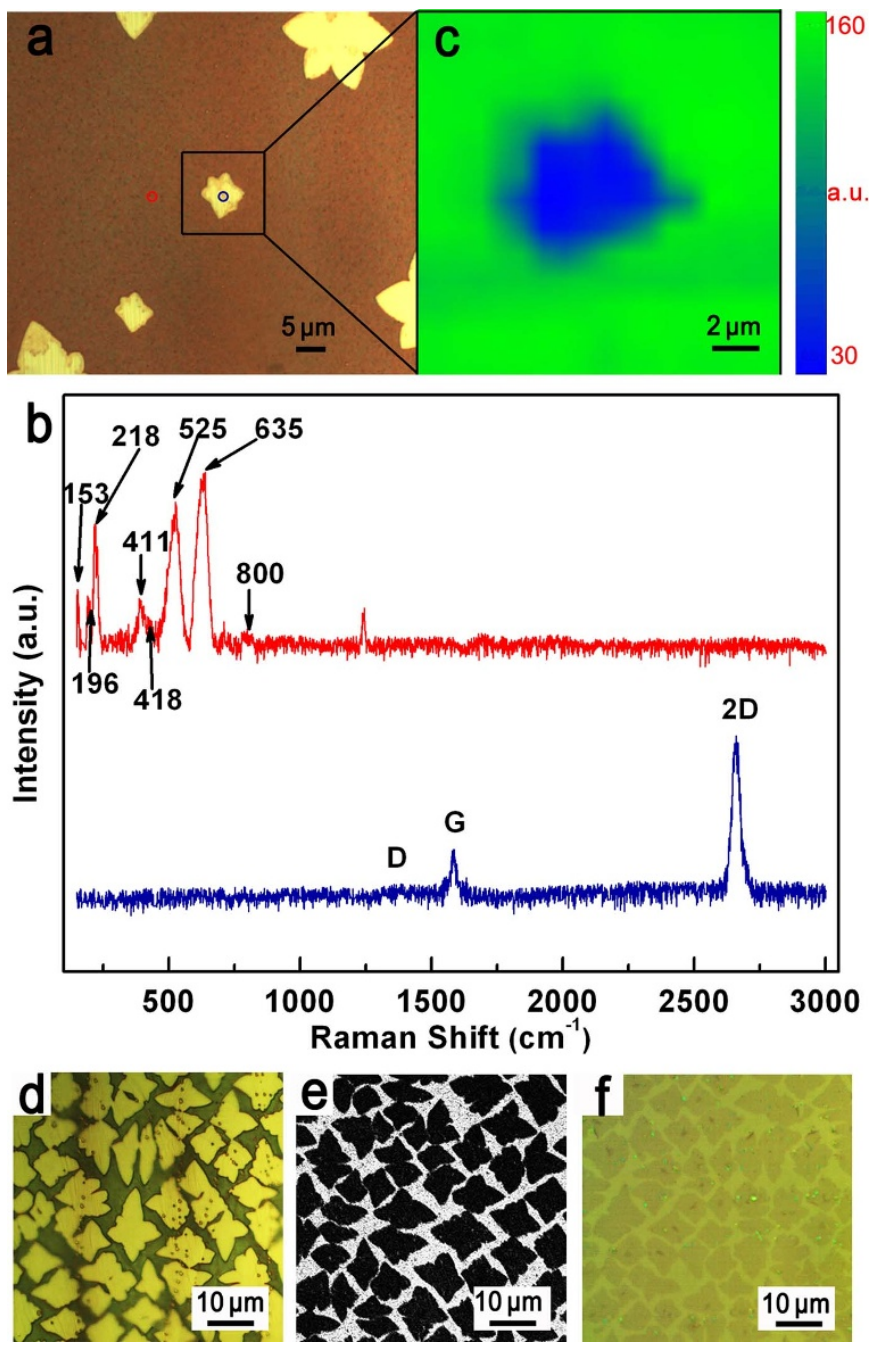

Figure $2 \mid$ Raman analysis after thermal annealing. (a) An optical micrograph of another $\mathrm{Cu} / \mathrm{pGr}$ sample after annealing. (b) Raman spectra collected from the red- and blue-circled regions in (a), respectively. (c) A spatial Raman map of the intensity of the $\mathrm{CuO}$ band at $635 \mathrm{~cm}^{-1}$ over the area with a black box $(20 \mu \mathrm{m} \times 20 \mu \mathrm{m})$ in (a). (d-e) Optical microscopic image and SEM image of the same Cu/pGr sample after annealing. (f) An optical micrograph of graphene films that have been transferred onto $300 \mathrm{~nm} \mathrm{SiO} 2 / \mathrm{Si}$ substrate. peak here. We found that, in comparison with the $\mathrm{Cu}$ sample, the $\mathrm{Cu} /$ pGr sample showed a higher peak of $\mathrm{Cu}\left(\mathrm{Cu}_{2} \mathrm{O}\right)$ and lower peaks of $\mathrm{CuO}$ and $\mathrm{Cu}(\mathrm{OH})_{2}$. In combination with the aforementioned single peak observation in the $\mathrm{Cu} / \mathrm{fGr}$ sample, these differences prove the partial oxidation of $\mathrm{Cu}$ due to the protection of graphene on top of it.

To further demonstrate the oxidation mechanism, micro-Raman spectroscopy with $632.8 \mathrm{~nm}$ laser was used to study the surface property of an annealed $\mathrm{Cu} / \mathrm{pGr}$ sample. In a blue-circled region, a small yellow graphene flake on the gray-red substrate was studied in detail (Fig. 2a). The Raman spectrum of the yellow region showed the distinct $\mathrm{G}\left(\sim 1580 \mathrm{~cm}^{-1}\right)$ and $2 \mathrm{D}\left(\sim 2660 \mathrm{~cm}^{-1}\right)$ peaks of graphene $\mathrm{c}^{24}$ with negligible peaks ascribed to $\mathrm{Cu}$ oxides and the $\mathrm{D}$ band of graphene (Fig. 2b). The intensity ratio of $I_{2 \mathrm{D}} / I_{\mathrm{G}}$ is about 2.9 and the half peak width of $2 \mathrm{D}$ peak is about $34 \mathrm{~cm}^{-1}$, which are characteristic of high-quality single-layer graphene $e^{24,32}$. These prove that the annealing process is nondestructive to graphene so that graphene remains pristine. In the control Raman spectrum from the gray-red substrate (red-circled), multiple peaks from 150 to $800 \mathrm{~cm}^{-1}$ appeared, which correspond to various copper oxides- $\mathrm{Cu}_{2} \mathrm{O}\left(153,196,218,525 \mathrm{~cm}^{-1}\right)$, $\mathrm{CuO}\left(411,635 \mathrm{~cm}^{-1}\right)$ and $\mathrm{Cu}(\mathrm{OH})_{2}\left(418,800 \mathrm{~cm}^{-1}\right)(\text { Fig. } 2 \mathrm{~b})^{30,33}$. This clearly demonstrates that $\mathrm{Cu}$ surfaces in the regions without graphene protection were oxidized during annealing. To probe the consistency, we screened the spatial map of the intensity of the $\mathrm{CuO}$ band at $635 \mathrm{~cm}^{-1}$ over the area with a black box $(20 \mu \mathrm{m} \times 20 \mu \mathrm{m}$, Fig. 2a). As shown in Fig. 2c, the Raman map does not indicate obvious peaks of the $635 \mathrm{~cm}^{-1}(\mathrm{CuO})$ band in the region under graphene, demonstrating that $\mathrm{Cu}$ in this region was intact after thermal treatment, and the unoxidized $\mathrm{Cu}$ region has the same profile as graphene. Therefore, we conclude that, due to the oxidation happening on $\mathrm{Cu}$ surfaces without graphene protection to form $\mathrm{Cu}$ oxides accompanied by significant changes in color, graphene becomes optically visible directly on the growth substrate.

To prove the reliability of the detection technique, we used both scanning electron microscopic (SEM) and optical methods to compare graphene morphologies on $\mathrm{Cu}$ substrates or $\mathrm{SiO}_{2} / \mathrm{Si}$ substrates after graphene transfer, respectively $y^{4,14,20,34}$. As shown in Figs. $2 d-f$, the optical image obtained by our annealing method on $\mathrm{Cu}$ foils displays almost the same graphene morphologies as those observed by SEM on the same sample or by the optical method on $\mathrm{SiO}_{2} / \mathrm{Si}$ substrates after graphene transfer. In addition, the SEM images from the same $\mathrm{Cu} / \mathrm{pGr}$ sample before and after annealing and optical micrographs of transferred graphene on $\mathrm{SiO}_{2} / \mathrm{Si}$ substrate are nearly identical to each other (Supplementary Fig. S2). These results consistently prove that our method is as reliable as traditional SEM and optical methods, but much more efficient due to its simplicity without complex transfer processes and the dependence on expensive equipments, therefore setting the foundation of the following studies.

\section{Discussion}

After having established this convenient method, we then turned our attention to exploring the effects of the factors, such as methane feeding rate $\left(J_{\mathrm{Me}}\right)$ or partial pressures $\left(P_{\mathrm{Me}}\right)$, temperature $(T)$, and substrate surface imperfection, on graphene growth. Firstly, by keeping the constant growth temperature at $1000^{\circ} \mathrm{C}$, we only changed $J_{\mathrm{Me}}$ from $1.0 \mathrm{sccm}$ with $P_{\mathrm{Me}}$ of $45 \mathrm{mTorr}$ to $0.3 \mathrm{sccm}$ with $P_{\mathrm{Me}}$ of $15 \mathrm{mTorr}$ for graphene growth for $1.5 \mathrm{~min}$. We found that the densities of graphene domains only showed a slight decrease as demonstrated in Figs. 3a and 3b. In contrast, when the growth temperature changed from $1000^{\circ} \mathrm{C}$ to $1020^{\circ} \mathrm{C}$ at constant gas feeding rate of $0.3 \mathrm{sccm}$ with $P_{\mathrm{Me}}$ of $15 \mathrm{mT}$ Torr for graphene growth for $1.5 \mathrm{~min}$, the densities of graphene domains decreased significantly but with the obvious increase of the domain size (Figs. $3 b$ and $3 c$ ). It was reported that suppressing the nucleation density of the substrates is important for growing graphene with large-size domain and high quality ${ }^{16,17,20}$. High growth temperature is helpful to reduce volatile impurities, contaminants, and defects on the copper surface and 


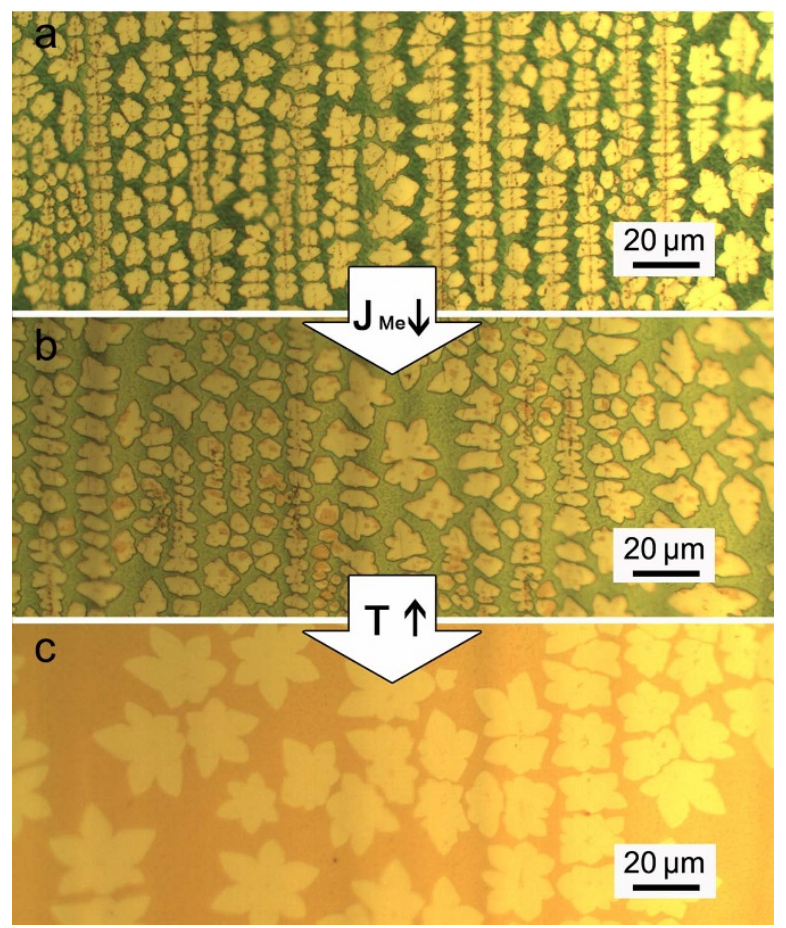

Figure $3 \mid$ Effects of temperature and gas feeding rate on graphene growth. Optical micrographs of $\mathrm{Cu}$ foils under different growth conditions after annealing: $T\left({ }^{\circ} \mathrm{C}\right) / J_{\mathrm{Me}}(\mathrm{sccm})$ for $1.5 \mathrm{~min}$ : (a) $1000 / 1.0$, (b) $1000 / 0.3$, (c) $1020 / 0.3$.

improve the surface flatness, thus resulting in the suppression of graphene nucleation. Therefore, the phenomena observed above in the current case can be explained as follows: Due to the reduction of graphene nucleation at higher temperature, each graphene domain tends to grow faster and larger when the gas feeding rate keeps constant. With the same density of graphene nucleation at the same temperature, it is reasonable that we did not observe the obvious differences in graphene growth when the gas feeding rates exceed the graphene growth rate. Consequently, it is clear that substrate surface imperfection (or temperature) considerably has more effect on graphene nucleation and growth kinetics, thus controlling graphene growth quality. This conclusion can be further corroborated by the following experiments.

To further investigate the effect of the gas feeding rate on graphene growth, another series of interesting experiments we performed are to study graphene growth at different positions on a large $\mathrm{Cu}$ foil. In this case, a $2 \mathrm{~cm} \times 6 \mathrm{~cm} \mathrm{Cu}$ foil was used for graphene growth under $1000^{\circ} \mathrm{C} / 1 \mathrm{sccm} \mathrm{CH}$ for $1.5 \mathrm{~min}$. After annealing treatment, obvious decreases in the size of graphene domains at the different positions of the same $\mathrm{Cu}$ foil along the forward direction of gas flow were observed (Figs. 4a-d). However, when we put the small pieces of different $\mathrm{Cu}$ foils at the similar positions used above along the direction of gas flow but without any other $\mathrm{Cu}$ foils ahead for graphene growth under the same condition (Supplementary Fig. S3), we found that the domain sizes in all the samples were nearly identical. We hypothesize that the possible reason for such an uneven growth on large $\mathrm{Cu}$ foils is that, as illustrated in Fig. 4e, with the depletion of gas carbon source $\left(\mathrm{CH}_{4}\right)$ the depletion thickness for $\mathrm{CH}_{4}$ mass transport to the $\mathrm{Cu}$ surface increases but the surface $\mathrm{CH}_{4}$ concentration decreases along the gas flow direction. As the growth rate for graphene domain is proportional to the surface carbon source concentration $^{21}$, it is not surprising that with the decrease of surface $\mathrm{CH}_{4}$ concentration the graphene domain sizes decrease along the direction of gas flow. Note that the densities of graphene nucleation at the different positions of the same $\mathrm{Cu}$ foils are close since the

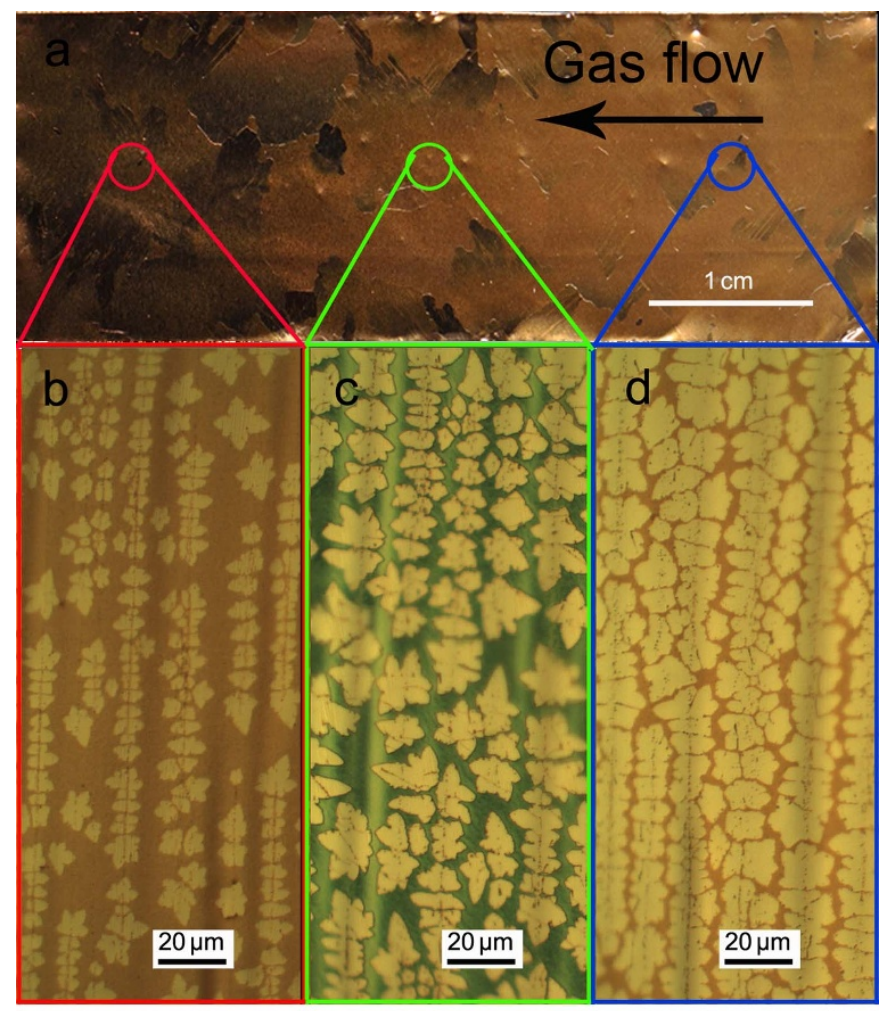

e

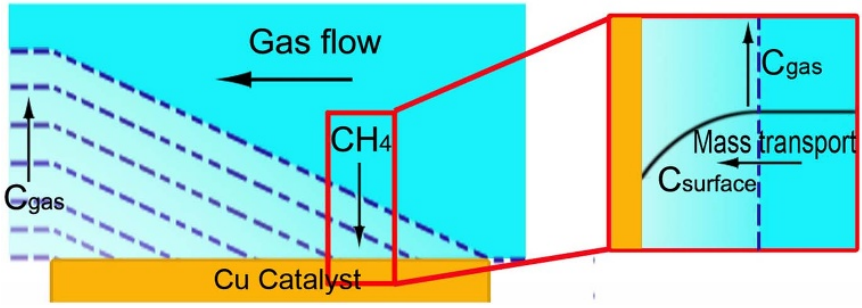

Figure $4 \mid$ Position effect on graphene growth. (a) Photograph of a large $\mathrm{Cu}$ foil after graphene growth under $1000^{\circ} \mathrm{C} / 1 \mathrm{sccm} \mathrm{CH}$ for $1.5 \mathrm{~min}$ and further annealing. (b-d) Optical micrographs of graphene observed at different spots along the gas flow direction. (e) A schematic diagram for the gas carbon source distribution during the growth.

temperature is the same (Supplementary Figs. S3-S4), which is consistent with the results discussed above.

Since our detection technique is developed directly on $\mathrm{Cu}$ substrates, graphene domains observed optically also reflect the surface properties of $\mathrm{Cu}$ substrates, thus in turn allowing us to study the effects of the morphology and impurity of $\mathrm{Cu}$ substrates on graphene growth. In most cases, parallel nucleation seeds along the waveshaped grains of $\mathrm{Cu}$ foils were observed (Fig. 3 and Supplementary Fig. S5). At higher growth temperature, the surface flatness and surface imperfection of the $\mathrm{Cu}$ substrate (as discussed above) are improved, and thus the nucleation density of seeds along the grains decreases (Fig. 3c). In the case of graphene growth on the inside of the $\mathrm{Cu}$ enclosure ${ }^{16}$, the number of nucleation seeds at the grains can be decreased because of the decrease of the concentration of the active gas (Supplementary Fig. S5). In both cases, graphene with large domains was obtained ${ }^{35-38}$. Therefore, decreasing defect sites on polycrystalline copper foils could afford high-quality graphene with large domain. In order to decrease the defects of the Cu surface, $\mathrm{Cu}$ foils were pretreated by acetic acid for $5 \mathrm{~min}$, and then washed with copious ultrapure water and ethanol. After acid pretreatment, the possible impurities and defects potentially as graphene nucleation sites were mostly removed. In comparison with $\mathrm{Cu}$ foils 
without any pretreatment, the density of graphene domains on $\mathrm{Cu}$ foils with acid pretreatment dramatically decreased from $800 \mathrm{ea} /$ $\mathrm{mm}^{2}$ (the number of domains per square micrometer) down to $40 \mathrm{ea} / \mathrm{mm}^{2}$ under $1020^{\circ} \mathrm{C} / 0.3 \mathrm{sccm} \mathrm{CH}$ for $1 \mathrm{~min}$ (Supplementary Fig. S6). Oxygen plasma was also used to remove the surface contaminants $^{39}$, however, it turned out to be that the pretreatment of oxygen plasma had no significant effect on the density of graphene nucleation (Supplementary Fig. S7). The reason for the nucleation decrease by acid pretreatment could be that with the aid of $\mathrm{O}_{2}$ in air, acetic acid etched the active defect sites and thus decrease the nucleation sites (Supplementary Fig. S6) ${ }^{40}$. Note that long-time acid pretreatment could overetch $\mathrm{Cu}$ foils and introduce new surface roughness, potentially increasing the graphene nucleation sites.

On the basis of deeper understanding of the interplay between the $\mathrm{Cu}$ surface and graphene growth, we are able to perform the holistic consideration for optimizing growth conditions. With high growth temperature and low methane flow rate, $\mathrm{Cu}$ substrates after proper acid pretreatment were used to grow high-quality graphene. With the growth time increase, larger and larger graphene domains were gradually obtained (Figs. 5a-c). As shown in Fig. 5d, graphene domains with the domain size as large as $\sim 100 \mu \mathrm{m}$ are achieved, much larger than the case reported previously under the similar growth conditions ${ }^{20}$.

Finally, it was found that the chemical concept of optical visualization of graphene domains directly on $\mathrm{Cu}$ substrates is universal and can be extended to other chemical reactions. In general, chemical reactions can transform $\mathrm{Cu}$ to its derivatives and correspondingly produce the interference color contrast between the naked $\mathrm{Cu}$ surface and that protected by graphene, thus making graphene optically visible. Previous reports demonstrated that sulfur and $\mathrm{H}_{2} \mathrm{O}_{2}$ could effectively react with $\mathrm{Cu}$ to form insoluble $\mathrm{Cu}$ compounds ${ }^{30,41}$. We then used sulfur in ethanol and $\mathrm{H}_{2} \mathrm{O}_{2}$ in water to possibly detect graphene growth through a solution process instead of thermal annealing. After immerging $\mathrm{Cu}$ foils into the saturated ethanol solution of sulfur for $\sim 30 \mathrm{~s}$, bright yellow graphene was developed from the black green substrate of copper sulfide (Supplementary Fig. S8b $)^{41}$. However, due to the high reactivity of sulfur with $\mathrm{Cu}$, sulfur can penetrate the graphene sheet through the edges ${ }^{42}$ and make graphene domains fuzzy. Remarkably, after development in $15 \% \mathrm{H}_{2} \mathrm{O}_{2}$ aqueous solution for $\sim 30 \mathrm{~s}$, we achieved optical micrographs with clear graphene profiles that are as good as those obtained by annealing (Supplementary Figs. S8a and S8c). Therefore, $\mathrm{H}_{2} \mathrm{O}_{2}$ is a good reagent to quickly characterize graphene domains and boundaries directly on $\mathrm{Cu}$ substrates through a solution method.

Taken together this study described our finding of a convenient detection technique for optically visualizing graphene domains and domain boundaries directly on growth substrates through either thermal annealing or solution treatment. Both thermal annealing and chemical treatment initiate the oxidation of the naked $\mathrm{Cu}$ to form $\mathrm{Cu}$ oxides accompanied by the interference color change, thus differentiating graphene from the substrate. By taking advantage of this method, we demonstrated the holistic consideration of the factors that control graphene nucleation and growth kinetics, such as growth temperature, gas feeding rate and substrate surface morphology, to realize individual high-quality graphene with the domain size as large as $\sim 100 \mu \mathrm{m}$, paving the way toward controllable synthesis of single-crystal graphene and large-scale fabrication of singlecrystalline defect-free graphene devices. Due to its simplicity, therefore, this nondestructive technique should open a universal and useful avenue for studying the intrinsic mechanism of graphene growth to elucidate the interplay among the parameters that control the grains, boundaries, structures and properties of graphene.

\section{Methods}

Copper substrate pretreatment. The pretreatment of copper foils is as follows: the copper foil was immerged into glacial acetic acid for $5 \mathrm{~min}$, rinsed by copious ultrapure water and ethanol for several times, and air-dried in a clean glass petri dish.
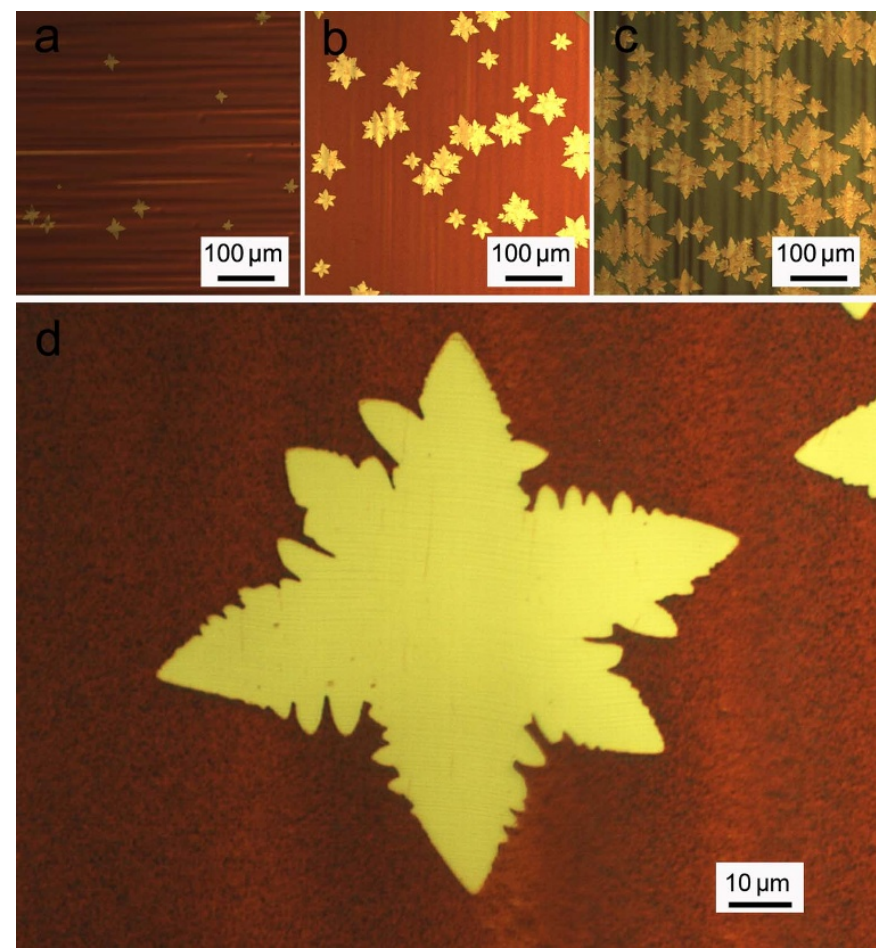

Figure 5 | Holistic optimization of growth conditions. Optical micrographs of acid-pretreated $\mathrm{Cu}$ foils under $1020^{\circ} \mathrm{C} / 0.3 \mathrm{sccm} \mathrm{CH}_{4}$ at the different growth time: (a) $1 \mathrm{~min}$, (b) $3 \mathrm{~min}$, (c) $6 \mathrm{~min}$. (d) The enlarged optical micrograph of a typical graphene domain.

Graphene growth. A split tube furnace with 1-inch quartz tube was used for graphene growth on $25 \mu \mathrm{m}$ thick copper foil (99.8\% Alfa Aesar \#13382) by a low pressure chemical vapor deposition (LPCVD) method $^{4}$. During the growth, copper foil was first annealed at a desired growth temperature for 30 min under $10 \mathrm{sccm} \mathrm{H}_{2}$ with a pressure of $450 \mathrm{mTorr}$; then, $\mathrm{H}_{2}$ was changed to $2 \mathrm{sccm}$ with a pressure of $95 \mathrm{mTorr}$ and a certain amount of $\mathrm{CH}_{4}$ was introduced to the furnace for graphene growth with a proper time; finally, the furnace quickly cooled down to the room temperature under a $10 \mathrm{sccm} \mathrm{H}_{2}$ gas flow. The control pure $\mathrm{Cu}$ foil without graphene growth also underwent the same process but without $\mathrm{CH}_{4}$ during treatments.

Thermal annealing and solution treatment. The development of graphene on $\mathrm{Cu}$ foils was carried out by heating the samples in air atmosphere on hot plate (IKA® CMAG HP7) at temperature of $160^{\circ} \mathrm{C}$ for $6 \mathrm{~min}$. For the development of graphene by solution method, the samples were immerged into the saturated solution of sulfur in ethanol or the $15 \% \mathrm{H}_{2} \mathrm{O}_{2}$ aqueous solution for $30 \mathrm{~s}$, rinsed by ultrapure water and dried by a nitrogen gas.

Characterization equipments. Optical microscopic images were obtained with a Nikon Eclipse LV100 POL Microscope. X-ray photoelectron spectroscopic (XPS) data were acquired from an ESCALab220i-XL electron spectrometer with a $300 \mathrm{~W}$ $\mathrm{AlK} \alpha$ radiation. Binding energies were referenced to the $\mathrm{C} 1 \mathrm{~s}$ binding energy at $284.5 \mathrm{eV}$. SEM image was taken with S-4800 UHR FE-SEM using a voltage of $1 \mathrm{KV}$. Raman spectra were collected using a micro-Raman spectroscope (Renishaw 1000), with an excitation wavelength of $632.8 \mathrm{~nm}$.

Graphene transfer. Transferring graphene to $300 \mathrm{~nm} \mathrm{SiO} / \mathrm{Si}$ wafer substrates was carried out as reported previously ${ }^{34}$. First, a layer of poly (methyl methacrylate) (PMMA) (MicroChem 495 PMMA A6) was spin-cast on Cu foils after graphene growth at $3000 \mathrm{rpm}$ for 30 second and baked at $180^{\circ} \mathrm{C}$ for $2 \mathrm{~min}$. Second, oxygen plasma was used to remove graphene on the back side of $\mathrm{Cu}$ foils. Next, copper was wet-etched in an aqueous solution of $\left(\mathrm{NH}_{4}\right)_{2} \mathrm{~S}_{2} \mathrm{O}_{8}$ for about 8 hours, resulting in graphene/PMMA films floating in the etchant. Then, the films were rinsed in ultrapure water for three times, transferred to $300 \mathrm{~nm} \mathrm{SiO}_{2} / \mathrm{Si}$ substrates and baked at $50^{\circ} \mathrm{C}$ for half an hour. Finally, PMMA was removed by annealing the samples at $420^{\circ} \mathrm{C}$ for $180 \mathrm{~min}$ under hydrogen $(600 \mathrm{sccm})$ and argon $(300 \mathrm{sccm})$ gas flow.

1. Geim, A. K. Graphene: status and prospects. Science 324, 1530-1534 (2009).

2. Castro Neto, A. H., Guinea, F., Peres, N. M. R., Novoselov, K. S. \& Geim, A. K. The electronic properties of graphene. Rev. Mod. Phys. 81, 109-162 (2009).

3. Zhu, Y. W. et al. Graphene and graphene oxide: synthesis, properties, and applications. Adv. Mater. 22, 3906-3924 (2010). 
4. Li, X. et al. Large-area synthesis of high-quality and uniform graphene films on copper foils. Science 324, 1312-1314 (2009).

5. Bae, S. et al. Roll-to-roll production of 30-inch graphene films for transparent electrodes. Nat. Nanotechnol. 5, 574-578 (2010).

6. Schwierz, F. S. F. Graphene transistors. Nat. Nanotechnol. 5, 487-496 (2010).

7. Lin, Y. M. et al. Wafer-scale graphene integrated circuit. Science 332, 1294-1297 (2011).

8. Bonaccorso, F., Sun, Z., Hasan, T. \& Ferrari, A. C. Graphene photonics and optoelectronics. Nat. Photonics 4, 611-622 (2010).

9. Li, X. M. et al. Graphene-on-silicon schottky junction solar cells. Adv. Mater. 22, 2743-2748 (2010)

10. Schwierz, F. Industry-compatible graphene transistors. Nature 472, 41-42 (2011),

11. Novoselov, K. S. et al. Electric field effect in atomically thin carbon films. Science 306, 666-669 (2004).

12. Emtsev, K. V. et al. Towards wafer-size graphene layers by atmospheric pressure graphitization of silicon carbide. Nat. Mater. 8, 203-207 (2009).

13. Dikin, D. A. et al. Preparation and characterization of graphene oxide paper. Nature 448, 457-460 (2007).

14. Liu, N. et al. Universal segregation growth approach to wafer-size graphene from non-noble metals. Nano Lett. 11, 297-303 (2011).

15. Reina, A. et al. Large area, few-layer graphene films on arbitrary substrates by chemical vapor deposition. Nano Lett. 9, 30-35 (2009).

16. Li, X. et al. Large-area graphene single crystals grown by low-pressure chemical vapor deposition of methane on copper. J. Am. Chem. Soc. 133, 2816-2819 (2011).

17. Yu, Q. et al. Control and characterization of individual grains and grain boundaries in graphene grown by chemical vapour deposition. Nat. Mater. 10, 443-449 (2011).

18. Wang, H. et al. Controllable synthesis of submillimeter single-crystal monolayer graphene domains on copper foils by suppressing nucleation. J. Am. Chem. Soc. 134, 3627-3630 (2012)

19. Zhang, Y. et al. Vapor Trapping growth of single-crystalline graphene flowers: synthesis, morphology, and electronic properties. Nano Lett. 12, 2810-2816 (2012).

20. Li, X. et al. Graphene films with large domain size by a two-step chemical vapor deposition process. Nano Lett. 10, 4328-4334 (2010).

21. Bhaviripudi, S., Jia, X., Dresselhaus, M. S. \& Kong, J. Role of kinetic factors in chemical vapor deposition synthesis of uniform large area graphene using copper catalyst. Nano Lett. 10, 4128-4133 (2010).

22. Zhang, Y. F. et al. Defect-like structures of graphene on copper foils for strain relief investigated by high-resolution scanning tunneling microscopy. ACS Nano $\mathbf{5}$, 4014-4022 (2011).

23. Wofford, J. M., Nie, S., McCarty, K. F., Bartelt, N. C. \& Dubon, O. D. Graphene islands on $\mathrm{Cu}$ foils: the interplay between shape, orientation, and defects. Nano Lett. 10, 4890-4896 (2010).

24. Ferrari, A. C. et al. Raman spectrum of graphene and graphene layers. Phys. Rev. Lett. 97, 187401 (2006)

25. Tao, L. et al. Synthesis of high quality monolayer graphene at reduced temperature on hydrogen-enriched evaporated copper (111) films. ACS Nano 6, 2319-2325 (2012)

26. Lu, A. Y. et al. Decoupling of CVD graphene by controlled oxidation of recrystallized $\mathrm{Cu}$. RSC Adv. 2, 3008-3013 (2012).

27. Blake, P. et al. Making graphene visible. Appl. Phys. Lett. 91, 063124 (2007).

28. Kim, D. W., Kim, Y. H., Jeong, H. S. \& Jung, H. T. Direct visualization of large-area graphene domains and boundaries by optical birefringency. Nat. Nanotechnol. 7, 29-34 (2012).

29. Liu, L. et al. Graphene oxidation: Thickness-dependent etching and strong chemical doping. Nano Lett. 8, 1965-1970 (2008).
30. Chen, S. et al. Oxidation resistance of graphene-coated $\mathrm{Cu}$ and $\mathrm{Cu} / \mathrm{Ni}$ alloy. ACS Nano 5, 1321-1327 (2011).

31. Espinos, J. P. et al. Interface effects for $\mathrm{Cu}, \mathrm{CuO}$, and $\mathrm{Cu}_{2} \mathrm{O}$ deposited on $\mathrm{SiO}_{2}$ and $\mathrm{ZrO}_{2}$. XPS determination of the valence state of copper in $\mathrm{Cu} / \mathrm{SiO}_{2}$ and $\mathrm{Cu} / \mathrm{ZrO}_{2}$ catalysts. J. Phys. Chem. B 106, 6921-6929 (2002).

32. Yan, K., Peng, H., Zhou, Y., Li, H. \& Liu, Z. Formation of bilayer bernal graphene: layer-by-layer epitaxy via chemical vapor deposition. Nano Lett. 11, 1106-1110 (2011).

33. Niaura, G. Surface-enhanced Raman spectroscopic observation of two kinds of adsorbed OH- ions at copper electrode. Electrochim. Acta 45, 3507-3519 (2000).

34. Reina, A. et al. Transferring and identification of single- and few-layer graphene on arbitrary substrates. J. Phys. Chem. C 112, 17741-17744 (2008).

35. Chen, H., Zhu, W. G. \& Zhang, Z. Y. Contrasting behavior of carbon nucleation in the initial stages of graphene epitaxial growth on stepped metal surfaces. Phys. Rev. Lett. 104, 186101 (2010).

36. Gao, J., Yip, J., Zhao, J., Yakobson, B. I. \& Ding, F. Graphene nucleation on transition metal surface: structure transformation and role of the metal step edge. J. Am. Chem. Soc. 133, 5009-5015 (2011).

37. Han, G. H. et al. Influence of copper morphology in forming nucleation seeds for graphene growth. Nano Lett. 11, 4144-4148 (2011).

38. Rasool, H. I. et al. Continuity of graphene on polycrystalline copper. Nano Lett. 11 , 251-256 (2011).

39. Sun, Z. et al. Growth of graphene from solid carbon sources. Nature 468, 549-552 (2010).

40. York, S. M., Haq, S., Kilway, K. V., Phillips, J. M. \& Leibsle, F. M. STM, FTIR and quantum chemical calculation studies of acetate structures on $\mathrm{Cu}(110)$ surfaces. Surf. Sci. 522, 34-46 (2003).

41. Thethwayo, B. M. \& Garbers-Craig, A. M. Laboratory scale investigation into the corrosion of copper in a sulphur-containing environment. Corros. Sci. 53, 3068-3074 (2011).

42. Sutter, P., Sadowski, J. T. \& Sutter, E. A. Chemistry under cover: tuning metalgraphene interaction by reactive intercalation. J. Am. Chem. Soc. 132, 8175-8179 (2010).

\section{Acknowledgements}

We acknowledge primary financial support from MOST (2009CB623703 and 2012CB921404), NSFC (20833001, 51121091, 2112016, and 21003002), FANEDD (2007B21), 111 Project (B08001), and BSTSP (2009A01).

\section{Author contributions}

C. J., J. J., S. L. and L. G. performed the experiments. C. J. and X. G. designed research and wrote the manuscript. All authors discussed the results and commented on the manuscript.

\section{Additional information}

Supplementary information accompanies this paper at http://www.nature.com/ scientificreports

Competing financial interests: The authors declare no competing financial interests License: This work is licensed under a Creative Commons

Attribution-NonCommercial-NoDerivative Works 3.0 Unported License. To view a copy of this license, visit http://creativecommons.org/licenses/by-nc-nd/3.0/

How to cite this article: Jia, C., Jiang, J., Gan, L. \& Guo, X. Direct Optical Characterization of Graphene Growth and Domains on Growth Substrates. Sci. Rep. 2, 707; DOI:10.1038/ srep00707 (2012). 